\title{
Emergency Aesthetic Approaches to Patients with Body Dysmorphic Disorder: Report of Three Cases
}

\author{
Behiye Sezgin Bolgül ${ }^{1}$, Engin Ağaçkıran², Emin Caner Tümen ${ }^{3}$, Yunus Ayna ${ }^{4}$, Sema \\ Çelenk ${ }^{5}$, Buket Ayna ${ }^{1}$ \\ ${ }^{1}$ Associate Professor, Dicle University, Faculty of Dentistry, Department of Pedodontics, Diyarbakır, TURKEY \\ ${ }^{2}$ Research Assistant, Dicle University, Faculty of Dentistry, Department of Pedodontics, Diyarbakır, TURKEY \\ ${ }^{3}$ Assistant Professor, Dicle University, Faculty of Dentistry, Department of Pedodontics, Diyarbakır, TURKEY \\ ${ }^{4}$ Research Assistant, Dicle University, Faculty of Arts, Department of Psychology, Diyarbakır, TURKEY \\ ${ }^{5}$ Associate Professor, Dicle University, Faculty of Dentistry, Department of Pedodontics, Diyarbakır, TURKEY
}

\section{Key Words}

Body dysmorphic disorder, physical appearance, aesthetic dentistry.

\section{Correspondence:}

Dr. Behiye SEZGİN BOLGÜL

Dicle University

Faculty of Dentistry

Department of Pedodontics

Diyarbakır, Turkey

Telephone: +90 (412) 2488101

e-mail: behiyebolgul@hotmail.com

\section{Abstract}

Body dysmorphic disorder (BDD) is an obsessive preoccupation with a perceived defect in one's physical appearance for which the individual persistently seeks medical attention and surgical correction. This preoccupation can be persistent and pervasive, leading to social withdrawal. A dentist may be the first health care worker who has an opportunity to intervene and assist these people in getting treatment. Patients may have unrealistic expectations for certain procedures, so assessing their psychological status is an important part of treatment planning and diagnosis. Patient expectations should be determined, and the ability to provide care that meets those expectations should be discussed. In the case reports, aesthetic treatments with composite resin restorations of three patients with BDD are reported.

The cases highlight the need for dentists to be educated on this disorder so that they can recognize and refer accordingly. There is also a need for interdisciplinary interactions between the dentist and the psychologist.

(Int Dent Res 2011;3:87-91)

\section{Introduction}

Body dysmorphic disorder (BDD) was previously known as dysmorphophobia and was originally described by Morselli in 1886 (1). People who have this disorder are preoccupied with certain aspects of their bodies and often seek to remedy their perceived flaws with cosmetic treatment. In addition to concerns about appearance, BDD is marked by avoidance of social situations, mirrors, posing for photographs, and bright lights (2).

BDD often goes unrecognized and undiagnosed because of patients' reluctance to divulge their symptoms because of secrecy and shame (2). Recognition and treatment are important because individuals with BDD have a poor quality of life and are socially isolated, depressed, and at high risk of committing suicide (3).

Although BDD has been described for more than a century, the true prevalence rate of BDD in the general population is not well known. Studies of the prevalence of BDD in psychiatric patients and the general population suggest that BDD is relatively common, affecting up to $2 \%$ of the general population $(4,5)$ and up to $12 \%$ of psychiatric patients $(6,7)$. 
A dentist may be the first health care worker who has an opportunity to intervene and asist these people in getting treatment. Patients may have unrealistic expectations for certain procedures, so assessing their psychological status is an important part of treatment planning and diagnosis. Patient expectations should be determined, and the ability to provide care that meets those expectations should be discussed (8).

In the case reports, aesthetic treatments with composite resin restorations of three patients who had BDD are reported.

\section{Case Reports}

All three patients were referred at different times by psychologist YA from Dicle University, Faculty of Arts, Department of Psychology, to Dicle University, Faculty of Dentistry, Department of Pedodontics with a diagnosis of Body Dysmorphic Disorder believed to be caused by unaesthetic tooth appearance.

\section{Case I}

Patient's anamnesis showed that she had no systemic diseases. Intraoral examination of this 11year-old female patient revealed devitalization due to a total crown crack in the maxillary left central tooth, caries at the interface in the maxillary right central tooth and maxillary right lateral tooth, and single-tooth anterior crossbite in the maxillary left lateral tooth (Fig. 1).

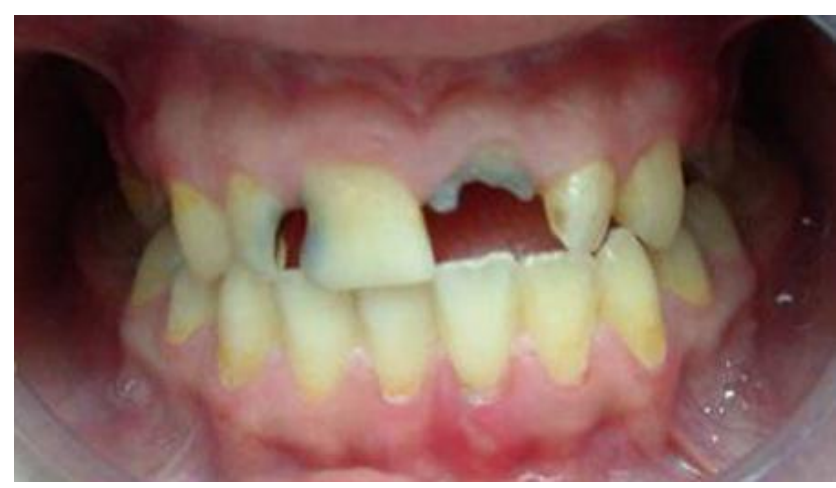

Figure 1. Pretreatment view of Case 1.

A single-session treatment procedure was planned for the patient. In a single session, the maxillary left central tooth was treated with root canal therapy, which was followed by fiber post application and restoration with crown fiber. The maxillary left lateral tooth was made to protrude by polyethylene fiber reinforced composite (FRC) (Ribbond Bondable Reinforcement Ribbon, Ribbond, Seattle, WA, USA) from its former retruded, displaced position. To eliminate interface caries and provide compatibility with the maxillary left central and lateral teeth, the maxillary right central and lateral teeth were positioned by FRC on the sagittal and frontal planes, and aesthetic composite laminate veneers were applied. (Fig. 2). The patient was then followed-up. She would then voluntarily come for follow-up visits, and the psychologist reported that she made progress.

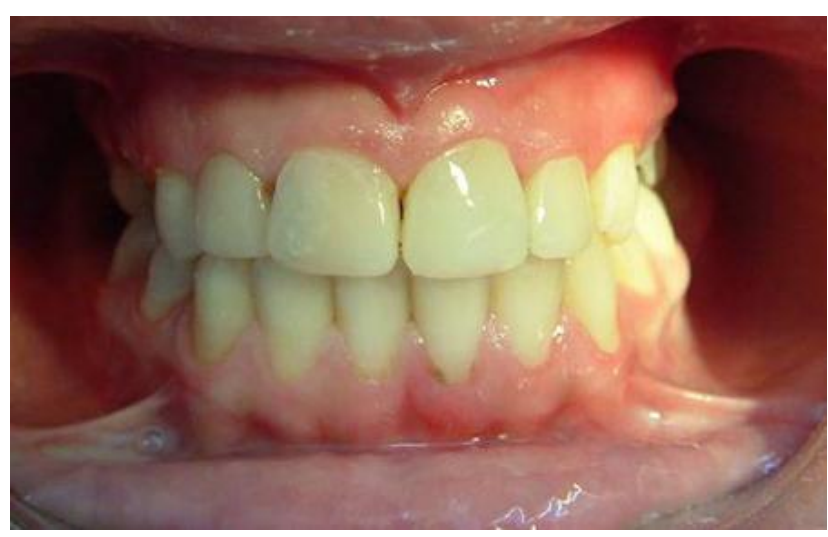

Figure 2. Post-treatment view of Case 1.

\section{Case II}

The anamnesis taken from a 13-year-old female patient revealed that the maxillary right and left central incisor teeth had been avulsed as a result of a trauma she experienced at the age of 7 ; that maxillary right and left lateral incisor teeth migrated to the spaces of the avulsed centrals as the required prosthetic treatments had not been performed; and thus, the maxillary canine teeth fully grew in place of the lateral incisor teeth (Fig. 3). The unaesthetic appearance was eliminated by converting canines to lateral teeth and lateral teeth to central teeth using composite restorations (Ecusit System, DMG Germany) (Fig. 4). The patient was then followedup. In examinations conducted 9 months later, it was observed that the patient did not have any problems and was satisfied with her aesthetic appearance.

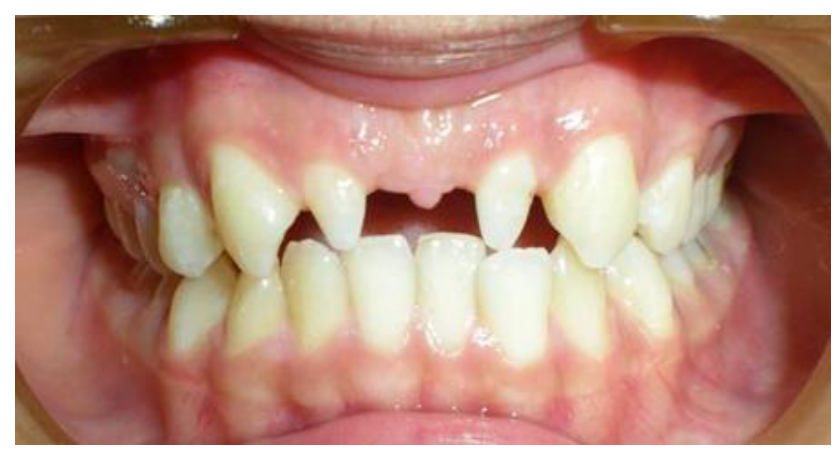

Figure 3. Pretreatment view of Case 2. 


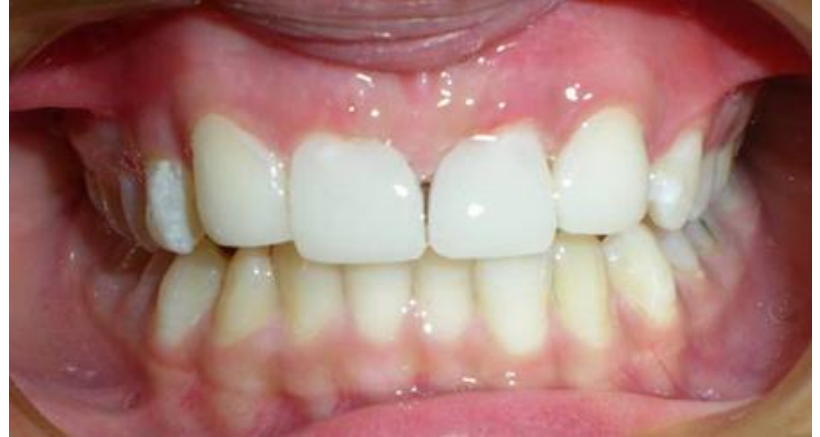

Figure 4. Post-treatment view of Case 2.

\section{Case III}

A 16-year-old female patient was diagnosed with diffuse hypoplasias. In her mouth, we observed unsuccessful composite restorations performed for fractures due to these hypoplasias (Fig. 5). Her anamnesis revealed that the patient complained about both the color and surface roughness of her teeth. A treatment plan was developed to improve the patient's appearance with a direct composite laminate veneer (Ecusit System, DMG Germany) (Fig. 6). The maxillary right central incisor, lateral incisor, and canine incisor and the left central incisor, lateral incisor, and canine incisor, which caused the patient's complaints, were restored with composite laminate veneers and the patient was then followed-up.

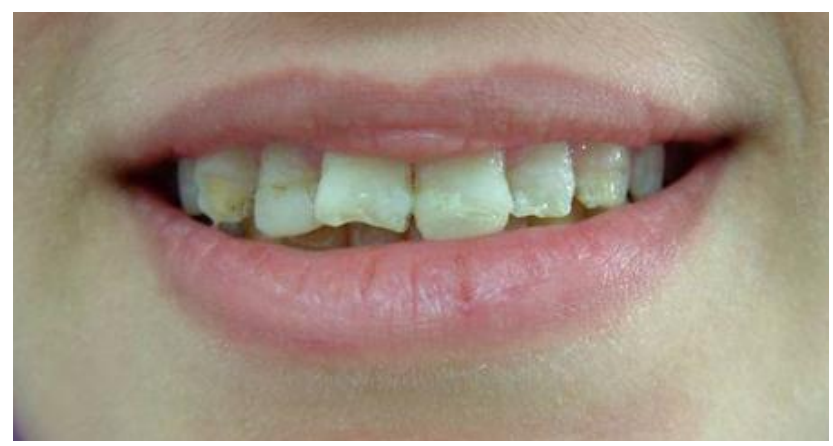

Figure 5. Pretreatment view of Case 3.

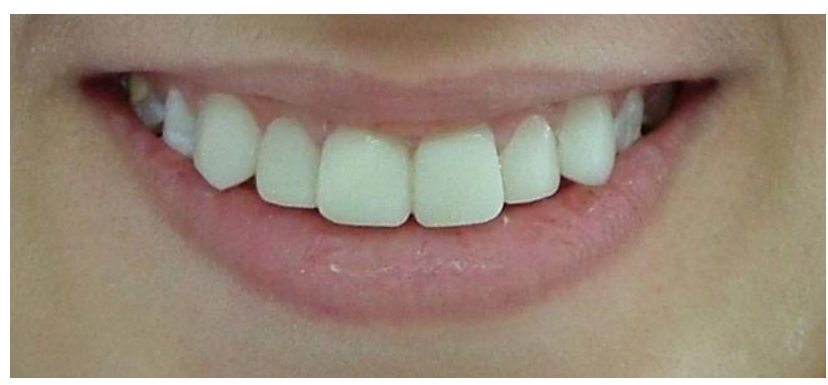

Figure 6. Post-treatment view of Case 3.

\section{Discussion}

A study has shown an interest in the effects of oral diseases and disorders on general health and quality of life. It has been suggested that anxiety, depression, and emotional fatigue are common complaints among individuals with chronic disorders (9).

Body dysmorphic disorder focuses on the patient's feelings of dislike or even loathing for some aspect of the body's appearance. Patients with body dysmorphic disorder have a pervasive subjective feeling of ugliness of some aspect of their appearance despite a normal or nearly normal appearance (10). BDD often goes unrecognized and undiagnosed because of patients' reluctance to divulge their symptoms because of secrecy and shame (2). Taqui et al. reported that about $60 \%$ of students with BDD tried to camouflage their perceived physical "defect," and 54\% had the habit of compulsively touching their physical "defect" (11). We observed that all of the three patients in our study covered their mouths with their hands while talking.

Studies and surveys have shown that dysmorphic concerns and body image dissatisfaction are increasing in the population $(12,13)$. BDD has been found to be more prevalent in student populations as compared to community samples (14-16). Our three patients were all students.

In clinical sample populations, the gender ratio has shown great variability. Two studies included more men than women $(17,18)$, two included more women than men $(19,20)$ and two included nearly equal proportions of men and women $(21,22)$. Our three patients were female.

Most studies have revealed that body shape, skin, and facial features are among the most common foci of concerns $(14,15,22)$. Cansever et al. showed the head/face area to be the most common body region of concern (70\%) (14). Taqui et al. reported that body foci of concern in 156 students were: being fat (49\%), skin (32\%), and teeth (23\%) (11). In our study, there was only one concern about the appearance of their body parts, which was their teeth.

The correction of a dental appearance problem can be justified as there is evidence of positive psychological change. Many general dental practitioners who practise aesthetic dentistry notice changes in their patients after treatment; a changed hairstyle and makeup; an open, relaxed, smiling posture; or more assertiveness are examples of some of these changes $(23,24)$. The success of an aesthetic rehabilitation depends on the understanding of the patient's needs and on effective communication among the entire dental team. 
In this century, the materials used for this purpose include silicate cements, acrylic resin, composite resins, and porcelains. However, their function has been to restore not only the appearance of teeth but, primarily, to replace tooth substance lost to dental disease. A conservative veneer technique is the application of a resin composite without tooth reduction or with minimal tooth reduction. Resin composite veneers can be altered and repolished in situ, and this feature is very useful when subtle changes to the emergence angles are desirable. Also, resin composite veneers are not as expensive as porcelain laminate veneers (25).

Composite laminate veneers may be an alternative method for these patients. Laminate veneers have become popular as a less invasive and more conservative treatment to provide a more pleasing appearance of the anterior teeth (26). The direct composite laminate technique has become more effective because of improvements in adhesive dentistry.

In this study, three patients who had dental problems and related psychological disorders were treated with composite resin restoration in one session. Although cosmetic correction of perceived physical deficits is rarely an effective treatment, it is concluded here that, with such restoration, aesthetic, functional, and especially psychological aspects of the patient's problems can be corrected.

The cases highlight the need for dentists to be educated in these disorders so that they can recognize and refer accordingly. There is also a need for interdisciplinary interactions between the dentist and the psychologist.

\section{Acknowledgments}

The authors deny any conflicts of interest related to this study.

\section{References}

1. American Psychiatric Association. Diagnostic and Statistical Manual of Mental Disorders. Ed. 4. Washington DC:American Psychiatric Press, 1994.

2. Agbelusi GA, Famuyiwa 0O. A case report of body dysmorphic disorder and literature review. West Afr J Med 2008;27(3):178-81.

3. Veale D. Body dysmorphic disorder. Postgrad Med J 2004;80(940):67-71.

4. Otto MW, Wilhelm S, Cohen LS, Harlow BL. Prevalence of body dysmorphic disorder in a community sample of women. Am J Psychiatry 2001;158(12):2061-63.

5. Faravelli C, Salvatori S, Galassi F, Aiazzi L, Drei C, Cabras P. Epidemiology of somatoform disorders: a community survey in Florence. Soc Psychiatry Psychiatr Epidemiol 1997;32(1):24-9.

6. Grant JE, Kim SW, Crow SJ. Prevalence and clinical features of body dysmorphic disorder in adolescent and adult psychiatric inpatients. J Clin Psychiatry 2001;62(7):517-22.

7. Zimmerman M, Mattia JI. Body dysmorohic disorder in psychiatric outpatients: recognition, prevalence, comorbidity, demographic and clinical correlates. Compr Psychiatry 1998;39(5):265-70.

8. Herren $C$, Armentrout $T$, Higgins M. Body dysmorphic disorder: diagnosis and treatment. Gen Dent 2003;51(2):164-6.

9. Locker D. Measuring oral health: a conceptual framework. Community Dent Health 1988;5(1):318.

10. Phillips KA. Body dysmorphic disorder: recognizing and treating imagined ugliness. World Psychiatry 2004;3(1):12-7.

11. Taqui AM, Shaikh M, Gowani SA, Shahid F, Khan A, Tayyeb SM et al. Body Dysmorphic Disorder: Gender differences and prevalence in a Pakistani medical student population. BMC Psychiatry 2008;8(20):1-10.

12. Sawer D. Awareness and identification of body dysmorphic disorder by aesthetic surgeons: results from a survey of American Society for Aesthetic Plastic Surgery members. Aesthetic Surgery Journal 2002;22(6):531-5.

13. Cash T, Winstead B, Janda L. The great American shape-up: body image survey report. Psychol Today 1986;20:30-7.

14. Cansever A, Uzun O, Dönmez E, Özşahin A. The prevalence and clinical features of body dysmorphic disorder in college students: a study in a Turkish sample. Compr Psychiatry 2003;44(1):60-4.

15. Bohne A, Wilhelm S, Keuthen NJ, Florin I, Baer L, Jenike MA. Prevalence of body dysmorphic disorder in a German college student sample. Psychiatry Res 2002;109(1):101-4.

16. Bohne A, Keuthen NJ, Wilhelm S, Deckersbach T, Jenike MA. Prevalence of symptoms of body dysmorphic disorder and its correlates: a crosscultural comparison. Psychosomatics 2002;43(6):486-90. 
17. Hollander E, Cohen L, Simeon D. Body dysmorphic disorder. Psychiatr Annals 1993;23:359-64.

18. Perugi G, Akiskal HS, Giannotti D, Frare F, Di Vaio $S$, Cassano GB. Gender-related differences in body dysmorphic disorder. J Nerv Ment Dis 1997; 185(9):578-82.

19. Phillips KA, Menard W, Fay C. Gender similarities and differences in 200 individuals with body dysmorphic disorder. Compr Psychiatry 2006;47(2):77-87.

20. Rosen JC, Reiter J. Development of the body dysmorphic disorder examination. Behav Res Ther 1996;34(9):755-66.

21. Phillips KA, Diaz SF. Gender differences in body dysmorphic disorder. J Nerv Ment Dis 1997; 185(9):570-7.

22. Fontenelle LF, Teles LL, Nazar BP, de Menezes $G B$, do Nascimento AL, Mendlowicz MV, Versiani M. A sociodemographic, phenomenological and long-term follow-up study of patients with body dysmorphic disorder in Brasil. International Journal of Psychiatry in Medicine 2006;36(2):243-59.

23. Kent G. Effects of ossointegrated implants on psychological and social well-being: a literature review. J Prosthet Dent 1992;68(3):515-8.

24. Kiyak $\mathrm{HA}$, Beach $B \mathrm{H}$, Worthington $\mathrm{P}$, Taylor $\mathrm{T}$, Bolender C, Evans J. The psychological impact of ossointegrated implants. Int J Oral Maxillofac Implants 1990;51(1):61-9.

25. Schmidseder J. Aesthetic Dentistry. New York:Thieme; 2000. p.125-31

26. Yüzügüllü, B; Tezcan, S. Comparative indications of laminate veneer restoration types used for colored and eroded teeth. Cumhuriyet University Faculty of Dentistry. 2005;8(2):133-7. 